\title{
Fotografía y comunicación: un espejo, una imagen, un ojo*
}

[Artículos]

Beatriz Múnera Barbosa**

Recibido: 26/11/202O

Aprobado: 27/12/202O

Citar como:

Múnera, B. (2021). Fotografía y comunicación: un espejo, una imagen y un ojo. Análisis, 53(98). https://doi.org/10.15332/21459169.6314

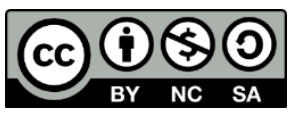

\section{Resumen}

La humanidad ha estado mediada por cambios de paradigmas que han hecho que se planteen nuevos caminos, tanto en la comunicación como en la percepción individual y colectiva, o en las maneras de narrar para pensar y contar la sociedad. Se modifica nuestra actitud ante perturbaciones tan rotundas como la que ahora vivimos con la pandemia provocada por la covid-19. Esta situación anómala entraña metamorfosis en la mentalidad de la época, de los valores que hasta ahora han formado una visión particular de la realidad.

Las fotografías son documentos sociales que narran, comunican y contribuyen a la historia y a la memoria individual y social. Las fotografías, como documento social que son, tienen su propia narrativa

\footnotetext{
* Artículo de reflexión.

** Doctora en Bellas Artes (UCM) y Profesora titular de Fotografía en la Facultad de Artes y Diseño de la Universidad de Bogotá Jorge Tadeo Lozano (Colombia). Correo electrónico: beatrize.munerab@utadeo.edu.co; ORCID: https://orcid.org/0000-00033092-4602
} 
comunicativa y son contribuciones a la historia y a la memoria (Múnera y Chaves, 2019). Una fotografía es siempre un recuerdo, una remembranza y, como ella, es frágil, se extravía, se desvanece, se pierde.

Hoy las imágenes nos reclaman una interpretación para comprender lo que nos narran; de ahí su gran poder comunicativo y su importancia para construir la realidad. Hemos hecho imágenes para testificar los hechos y para evocar las ausencias. ¿Pero qué ocupaba el lugar de la fotografía antes que ella? Siempre se ha dicho que el grabado, la pintura, el dibujo, pero una respuesta también podría ser la memoria, en la que se nos puede presentar como un espejo, como una imagen, como un ojo.

Esta reflexión alrededor de la fotografía en la docencia y su lugar en medio del confinamiento por la pandemia surge como una preocupación frente a su papel para la gestión de la vida personal y social, y sobre cómo va a significar los hechos.

Palabras clave: fotografía, comunicación, pantallas, cuerpos.

\section{Photography and communication: a mirror, an image, an eye}

\section{Abstract}

Humanity has been mediated by paradigm shifts that have led to new paths being proposed, both in communication and in individual and collective perception, or in the ways of narrating to think and tell society. Our attitude is changing in the face of disturbances as categorical as the one we are now experiencing with the pandemic caused by COVID-19. This anomalous situation entails metamorphosis in the mentality of the time, of the values that until now have formed a particular vision of reality.

Photographs are social documents that narrate, communicate and contribute to history and to individual and social memory. Photographs, as the social document they are, have their own communicative narrative and are contributions to history and memory (Múnera y Chaves, 2019). 
A photograph is always a memory, a remembrance, and like them, they are fragile, they are misplaced, they fade, they are lost.

Today, images demand an interpretation in order to understand what they convey; hence their great communicative power and their importance in constructing reality. We have made images to testify the facts and to evoke absences. But what occupied the place of photography before? It has always been said that engraving, painting, drawing, but one answer could also be memory, which can be presented to us as a mirror, an image, an eye.

This reflection around photography in teaching and its place in the midst of the pandemic arises as a concern regarding its role for the management of personal and social life, and how it will signify the events.

Keywords: photography, communication, screens, bodies.

\section{Fotografia e comunicação: um espelho, uma imagem, um olho}

\section{Resumo}

A humanidade tem sido mediada por mudanças de paradigma que levaram à proposta de novos caminhos, tanto na comunicação quanto na percepção individual e coletiva, ou nas formas de narrar para pensar e contar à sociedade. Nossa atitude para pertubações tão instensas como a que estamos experimentando agora com a pandemia provocada pela covid-19 está mudando. Essa situação anômala implica metamorfose na mentalidade da época, dos valores que até agora formavam uma visão particular da realidade.

Fotografias são documentos sociais que narram, comunicam e contribuem para a história e memória individual e social. As fotografias, como documento social que são, têm sua própria narrativa comunicativa e são contribuições para a história e para a memória (Múnera e Chaves, 
2019). Uma fotografia é sempre uma memória, uma lembrança e, como ela, é frágil, extravia-se, desaparece e perde-se.

Hoje as imagens exigem uma interpretação para entender o que elas nos narram; daí seu grande poder comunicativo e sua importância para construir a realidade. Fizemos imagens para testemunhar os fatos e evocar as ausências. Mas o que ocupava o lugar da fotografia antes dela? Sempre foi dito que era a gravura, a pintura e o desenho, mas uma resposta também poderia ser a memória, na qual podemos ser apresentados como um espelho, como uma imagem, como um olho. Essa reflexão em torno da fotografia no ensino e seu lugar no meio do confinamento pela pandemia surge como uma preocupação sobre seu papel na gestão da vida pessoal e social, e sobre como isso significará os fatos.

Palavras-chave: fotografia, comunicação, telas, corpos.

$$
\begin{array}{r}
\text { Lo que convierte a la fotografía en } \\
\text { una extraña invención -con } \\
\text { consecuencias imprevisibles- es } \\
\text { que su materia prima fundamental } \\
\text { sea la luz y el tiempo } \\
\text { (Berger y Mohr, 2008) }
\end{array}
$$

\section{Introducción}

El momento que vivimos durante la actual crisis sanitaria ha puesto de manifiesto el valor que tiene la expresión artística como metodología para permitirnos pensar e incluir cambios en las didácticas de clase y en la exploración de recursos diversos y transdisciplinares.

La fotografía es una herramienta para la creatividad y la expresión, y es heredera directa de las bellas artes. Teniendo en cuenta lo anterior, la exploración y el análisis de obras artísticas para construir sentidos pedagógicos en el aula (física o virtualmente) es primordial. 
Con apreciación e investigación académica, dimensionamos los aportes del arte para nuestro objeto de estudio y para aumentar la sensibilidad de los estudiantes y su conocimiento.

Man Ray y Magritte, artistas pioneros y revolucionarios con sus obras, nos transmiten, transgreden, comunican y nos permiten pensar para transformar nuestros modos de ver y contar con la fotografía. Nos dan indicios para imaginar el futuro desde las imágenes y que estas, a su vez, nos den luces para poder entender el mundo.

\section{¿Qué fotografía?}

En las clases de fotografía he procurado provocar en mis estudiantes discusiones e inquietudes en torno a lo fotográfico en la pandemia. No solo lo intento desde el lugar de la enseñanza de los contenidos mismos de la fotografía (técnica, teoría, crítica, apreciación, creatividad, etc.), sino también desde la experiencia con la imagen en esta nueva comunicación diversa y virtual que estamos viviendo hoy en todo el planeta.

¿Qué es lo que estamos experimentando en estos meses de aislamiento, de ruptura con la vida social? No solamente vivimos la distancia física obligada, sino que sufrimos la "ausencia del cuerpo", lo que da lugar a nuevos rituales comunicativos y fotográficos que seguramente permanecerán en el tiempo:

Narramos con imágenes desde la prehistoria y hoy hemos cambiado las herramientas, pero seguimos teniendo la misma finalidad: situarnos en el mundo, decir quiénes somos y qué hacemos, en definitiva, contar y contarnos. Porque la fuerza de las imágenes fotográficas proviene de que son realidades materiales por derecho propio, medios poderosos para poner en jaque lo que nos rodea, para transformarlo. (Múnera, 2020, p. 4) 
Estamos asistiendo a una metamorfosis inesperada en la que

[...] el virus ha cambiado la comunicación que teníamos, ya de por sí en continua metamorfosis, de una manera drástica. Todo lo comunicativo ha sido invadido por el coronavirus: pantallas, redes virtuales, portadas, noticieros y hasta las ínclitas noticias falseadas (fake news). (Peña Sarmiento et ál., 2020, p. 14)

Más allá de ese ejercicio pedagógico con y desde la fotografía como objeto de estudio, constatamos el uso y la circulación vertiginosa de la imagen en la red, de modo que afloran en su complejidad nuevas preguntas que profundizan la ambigüedad de lo fotográfico. Surgen nuevas divagaciones sin necesidad de adentrarnos en una reflexión que nos lleve de lo puramente empírico a lo puramente estético. Lo valioso aquí es rescatar cómo la fotografía nos lleva a la cuestión del "significado de las apariencias en sí mismas".

En Otra manera de contar (2008), Berger y Mohr pusieron en tensión el quehacer fotográfico, el estatuto de lo fotografiado, la imagen y el lugar del espectador. Sostuvieron que no hay fotografías que puedan ser negadas; por el contrario, todas las fotografías poseen categoría de realidad. Lo que ha de examinarse es de qué modo la fotografía puede o no dar significado a los hechos.

Hoy podemos añadir a sus reflexiones preguntas como ¿qué fotografías estamos produciendo y haciendo circular?:

Las imágenes e interacciones-bit se han multiplicado al ser nuestra vida online la vida "normal", han pasado a ser casi la totalidad de nuestro yo y hemos inundado, más aún si cabe, el mundo (¿qué es hoy el mundo?) con videos, fotografías y montajes de la nueva realidad que estamos viviendo (Chaves et ál., 2020, pp. 236-237) 
¿Qué significan esas imágenes? ¿Qué estamos comunicando con ellas? Tal vez, como se preguntan Chaves et ál., estemos comunicando las imágenes que construimos desde la vulnerabilidad en la que nos ha situado la incertidumbre provocada por el coronavirus. Esta reflexión se basa en el valor y la incidencia de tres imágenes históricas que dicen mucho de nuestra realidad hoy, en torno a la comunicación y la fotografía.

\section{Una imagen}

Figura 1. Ma dernière photographie (Mi última fotografía), Man Ray, 1929.

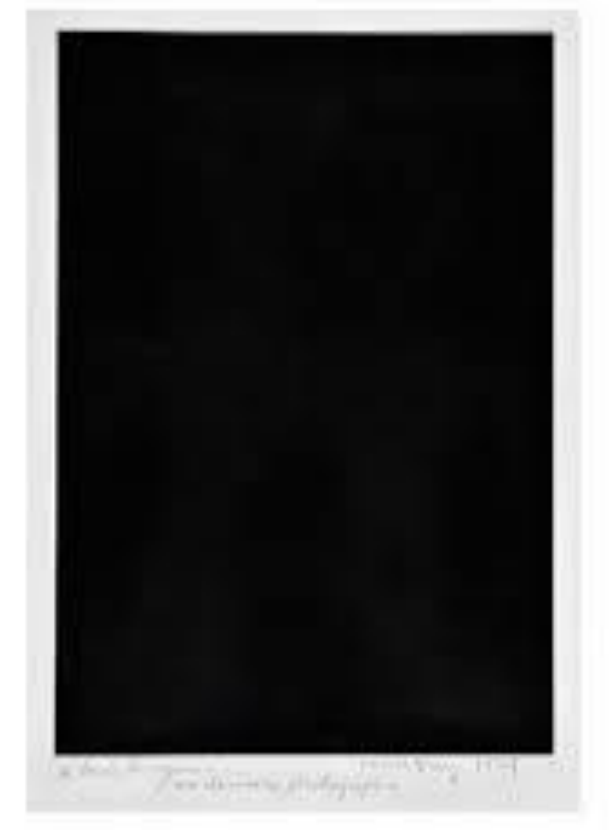

Fuente: Man Ray (1929).

La obra de Man Ray, dedicada al poeta francés Louis Aragon, es un rectángulo de fondo negro en formato vertical (figura 1). Una superficie oscura en donde metafóricamente estaría el compendio de todas las imágenes y donde paradójicamente no podemos ver ninguna. Una imagen que supone una síntesis de la actualidad que vivimos. 
Parece obvio para todos expresar que padecemos una hiperpolución de imágenes sin precedentes, que no son los excedentes de una sociedad hipertecnificada sino, más bien, que constituye la sintomatología de nuestra actual cultura. Ciertamente, en este lugar donde irrumpe la fenomenología posfotográfica, se acentúa más en estos tiempos con la facilidad para producir y difundir imágenes.

La posfotografía hace alusión a la imagen fotográfica que fluye en el espacio híbrido de la sociabilidad digital y es consecuencia de la superabundancia visual. Si antes decíamos que no podíamos entender las imágenes, que no logramos decodificarlas, la pregunta entonces es: ¿qué estamos haciendo o pretendiendo hacer con ellas? Las preguntas de Berger y Mohr vuelven a ser pertinentes y oportunas casi cuarenta años después.

La cantidad de imágenes en la red, y su desbordada producción y circulación ponen en entredicho su propio sentido, ¿quién las ve? Parecería que afianzamos con ella, con la imagen, nuestra existencia. Las fotografías se convierten en evidencias de lo cotidiano, no sabemos si de una manera significativa y contundente de lo que hacemos, vivimos y sentimos.

Por otro lado, esta cantidad de imágenes excedidas se convierten en hipercontaminación, en una suerte de espectáculo descontrolado, inconexo y sin sentido, "porque la fotografía y la imagen pueden, en función de su uso, producir conocimiento, reconocimiento, pero también exclusión o marginación” (Chaves et ál., 2020, p. 240).

Lo positivo que podría tener este sinsentido es que se ha creado una nueva categoría que Fontcuberta define como la fotografía conversacional.

Las fotos pasan a actuar como mensajes que nos enviamos unos a otros.

Antes la fotografía era una escritura, ahora es un lenguaje. Nos

comunicamos con fotos con total naturalidad, como si la fotografía 
rebasase el estadio del texto impreso para conquistar el estadio del lenguaje oral. Ahora las fotografías también funcionan como palabras dichas, como palabras habladas que una vez alcanzan a su receptor ya no hay necesidad de guardar, pues ya han cumplido su misión comunicativa. (Fontcuberta, 2016, p. 119)

Este es un reconocimiento más, y no menor, al valor comunicativo de las imágenes. De esta manera ya no somos los que éramos, y la comunicación y la fotografía tampoco: "Ya no somos quienes alguna vez fuimos. Para bien o para mal. Ya no pensamos, hablamos, leemos, escuchamos, ni miramos como alguna vez lo hicimos" (Ritchin, 2010, p. 9).

Los cambios en los medios masivos de comunicación, especialmente los que conocemos como digitales, y en la situación actual, nos han obligado a vivir de otra manera, con percepciones y expectativas que se transforman todos los días, para bien o para mal, acompañados por algunos segundos de imágenes efímeras, anónimas, sin contexto, que olvidamos rápidamente.

Las imágenes circulan, sentimos que nos entretienen, las compartimos y percibimos el vacío de la incertidumbre, advertimos la ausencia de sentimientos aun no expresados. Una vez sumidos en los medios y en la hipercontaminación de imágenes, ¿̇cómo conocer los efectos que tienen y tendrán en nosotros?

Lo sorprendente del momento que vivimos es que estamos abocados a la virtualidad, al intento de llevar a cabo una comunicación eficaz en y por la red, a realizar procesos educativos y formativos, a narrar con imágenes. Somos de manera simultánea exploradores inmersivos, usuarios de este frágil y potente universo que nos está reinventando a nosotros mismos, cambiando nuestras antiguas nociones de cuerpo, tiempo, comunidad, mundo. 


\section{Un espejo}

Figura 2. L'Image parfaite (La imagen perfecta, René Magritte, 1928)

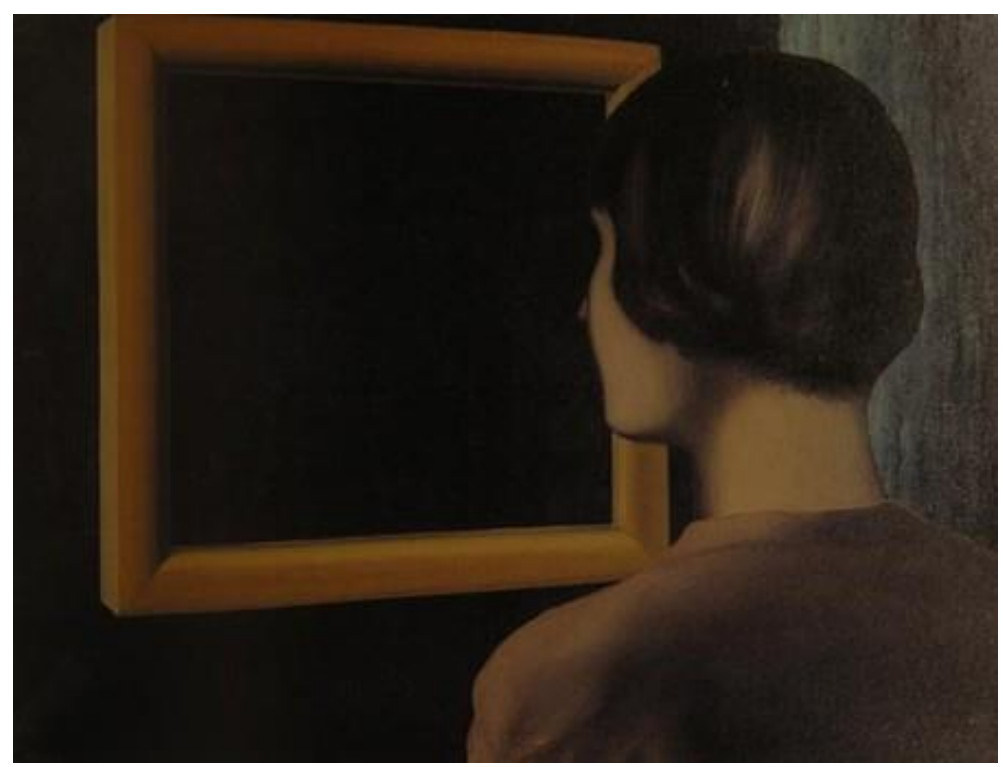

Fuente: Magritte (1928).

Magritte propone una imagen perfecta donde no se ve nada y está todo (figura 2). Aquí se juntan el sentido del vacío y, a la vez, la imagen resumen y totalizadora. En este caso, el fondo oscuro que no muestra nada pero lo contiene todo, está siendo observado por alguien.

Estamos asistiendo a una danza sélfica en la pantalla del computador en la que esta unge como espejo y nos muestra a veces, los reflejos de los nuevos narcisos. Esta vida, anómala e inclasificable, es nuestra cotidianidad. El aula de clase pasó a ser invertida en el sentido literal y metafórico. Estamos reconstruyendo no solo su funcionalidad, sino también sus sentidos. De igual manera los enunciados fotográficos ya son otros, deben ser otros porque no somos los mismos.

El hoy visual es mayoritariamente autorreferencial, es un síndrome de época. Es el yo sélfico que dice "he estado ahí" y eso que existe en el mundo estará detrás de mí como un fondo. Es un ejercicio de 
autorrepresentación, de referenciarnos a nosotros mismos, que nos viene bien si nos permitiera entender la turbación, la ansiedad, el pánico tal vez, la incertidumbre de nuestra vida presente y futura.

La fotografía ha tenido unos usos sociales a través de su historia, pues ha documentado en imágenes fijas instantes aislados de tiempo. Una imagen como resultado de "esto es lo que veo". Un daguerrotipo como imagen fundacional nos indica "esto ha sido" y opera como un registro, una evidencia de un suceso para la posteridad, un hecho congelado de lo “otro", de lo que veo o, mejor aún, de la "otredad”, sea esta un paisaje, un lugar, una persona, un monumento o un oscuro vacío.

Nos hemos convertido en eso que he denominado "los nuevos hombres y mujeres de Vitruvio", figuras no inscritas en una circunferencia marcada con un compás como lo planteó Leonardo da Vinci y que se ajustan al canon de las proporciones humanas.

Nuestra escala y proporción hoy es la pantalla. No es ahora el estudio de las proporciones ideales del cuerpo humano, sino la pantalla la que nos contiene, la que nos concede nuestro límite o extensión, la que da cuenta de "nuestras medidas". Unas medidas en las que la figura de cuerpo entero es sustituida por el busto, el centro es el rostro que a veces se nos oculta y aparece como un círculo que engloba unas letras o que no contiene más que un vacío fondo oscuro, como las dos imágenes comentadas hasta ahora.

Hoy vivimos el "aquí estoy” y “esto está sucediendo" en simultáneo. Podemos afirmar que en esta civilización de la imagen, los espejos y las pantallas cumplen diversas funciones: el gusto por mirarnos, el gusto por mirar a las otras personas, por inmiscuirnos en el espacio íntimo del otro, por invadir su territorio desde lo virtual y también el gusto por compartir todas estas miradas. 


\section{Un ojo}

Figura 3. Le faux miroir (El espejo falso, René Magritte, 1928). "Buscar un espejo, una imagen, un ojo. Encontrarte en el reflejo e ignorar quién eres" (Bosch, 2005)

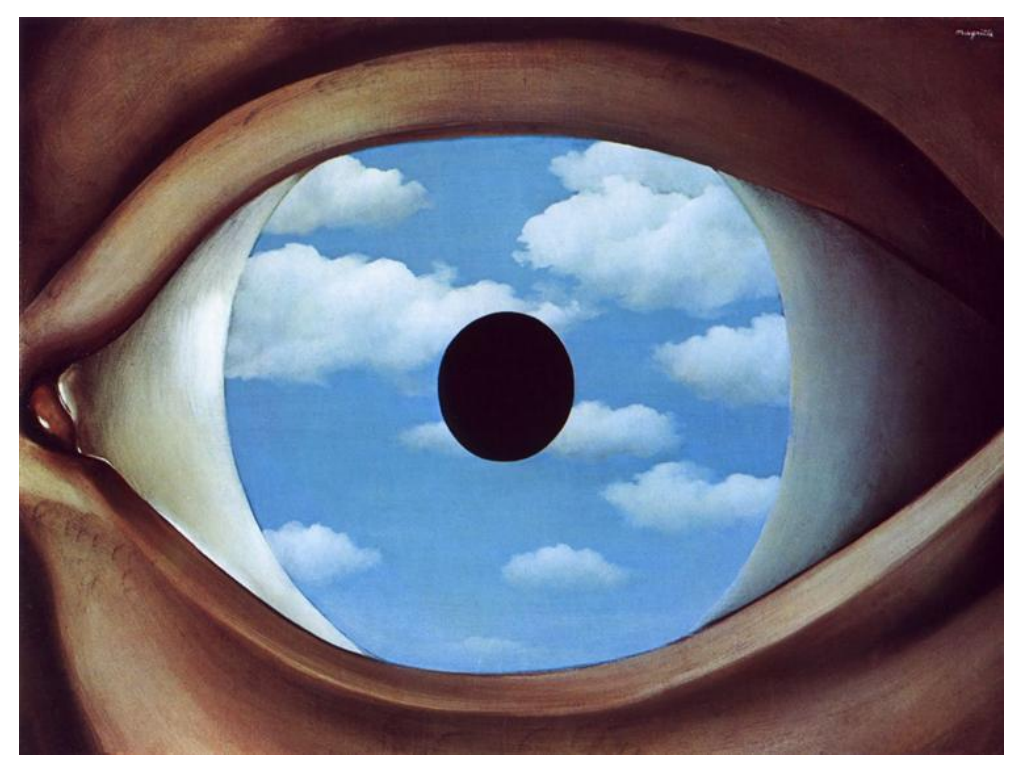

Fuente: Magritte (1929).

En su libro Esto que ves es un rostro, Bosch (2005) recurre a la voz narrativa en primera persona para desarrollar un delirio; podría llamarse un momento de locura. Es la experiencia de un cuerpo en un espacio cerrado: un manicomio. Un cuerpo fragmentado en todas sus posibilidades que no encuentra unidad posible en el reflejo del espejo. Es un cuerpo limitado, fronterizo, nómada. Así, se refleja el "no cuerpo" en la pantalla, contenido en ella. Observamos y somos observados.

Todo se ofrece a una visión absoluta y a todos nos guía el placer de mirar. Sería entonces como una especie de gran hermano que pierde el carácter centralizado, autoritario y represivo y que se abre a un sistema democrático, voluntario y participativo en el que terminamos todos cumpliendo los distintos roles: de observadores y también de observados. 
Tiempo, espacio y cuerpo, en la simultaneidad, pareciera que hacen eco de la famosa red de miradas que nos anunciara Berger: "Todo el que ve puede ser visto", o de las apuestas de autores como Antonio Machado (2016) para quien "el ojo que ves no es ojo porque tú lo veas, es ojo porque te ve", o Jean Paul Sartre (2016) que parafrasea a Descartes al afirmar que "Me miran, luego existo". Mientras para Sartre la mirada del otro me vuelve una cosa, para Machado es esa mirada la que le hace a uno ser, "ser otro". Espejos, cámaras y pantallas pasan a definir los nuevos sentidos de lo panóptico y lo escópico de nuestra sociedad. El ojo pintado por Magritte es espejo y recuerda el ojo descrito por Dziga Vertov en El hombre de la cámara (1929, en Berger, 2007):

Soy un ojo, un ojo mecánico. Yo, la máquina, os muestro un mundo del único modo que puedo verlo. Me libero hoy y para siempre de la inmovilidad humana. Estoy en constante movimiento. Me aproximo a los objetos y me alejo de ellos. Repto bajo ellos. Me mantengo a la altura de la boca de un caballo que corre. Caigo y me levanto con los cuerpos que caen y se levantan. Ésta soy yo, la máquina, que maniobra con movimientos caóticos, que registra un movimiento tas otro en las combinaciones más complejas. (Berger, 2007, p. 24)

El párrafo anterior nos abre el camino hacia esa reflexión magnífica de que para bien o para mal el destino del fotógrafo está vinculado irremediablemente a los destinos de la máquina. Somos artefacto, prótesis; somos herramienta, cámara. Tenemos la necesidad de acercar las cosas, de atraerlas para sí y asirlas. Lo hacemos con la extensión del ojo y de la mano que se choca con la pantalla y su reflejo; nuestros destinos hoy están vinculados a los destinos de las máquinas. Sean estas la pantalla del computador, el celular, la tableta o cualquier aparato tecnológico con capacidad para que veamos y seamos vistos. 
Para mí, el ruido del Tiempo no es triste: me gustan las campanas, los relojes... y recuerdo que originariamente el material fotográfico utilizaba las técnicas de la ebanistería y de la mecánica de precisión: los aparatos en el fondo, eran relojes para ser contemplados y quizás alguien de muy antiguo en mí oye todavía en el aparato fotográfico el ruido viviente de la madera. (Barthes, 1989, p. 44)

Pero la cámara que usamos no solo la anteponemos a los ojos, fotografiamos tal vez con todo el cuerpo, congelamos apariencias, semblantes. Esta realidad limitada y acotada por paredes y ventanas se convierte en paradigma de registro, del no registro, de la no memoria, de la no huella.

\section{La docencia fotográfica}

Los cambios se suceden con rapidez, sufrimos trasformaciones vertiginosas de la realidad social y el profesorado debe dar a las y los estudiantes respuestas en tiempo real con acciones pedagógicas y disciplinares que no solamente cubran sus expectativas, sino que además estén orientadas a lograr su desarrollo como seres humanos sensibles y sostenibles que comprenden las múltiples realidades y las transformaciones sociales que, muchas veces, son representadas en imágenes.

Nuestro lugar es más de mentoras, de guías para investigar, acompañar a los estudiantes en sus intereses y ayudarlos a tener pensamiento propio y capacidad crítica para intentar tener conciencia de su contexto. El conocimiento y comprensión de los contenidos teóricos es posible que sean abordados con el debido acompañamiento y con los recursos que la tecnología digital nos proporcionan, pero los niveles más complejos de aprendizaje, el análisis y el pensamiento crítico no son sustituibles o resueltos por la tecnología. 
Fotografiar es, sin duda, alejarse de lo capturado, pero también es una manera de conservarlo para siempre. Por las imágenes hemos conocido el mundo y su representación, hemos construido imágenes para la historia. Puede que con el tiempo todo desaparezca y que solamente las imágenes nos sobrevivan. Puede que también nos determinen y que necesitemos comprenderlas para que, en esta época en la que vivimos consumiendo imágenes, no nos consuman. De ahí la importancia de abordar en clase los sentidos y los significados de la fotografía, y más en tiempos de pandemia.

\section{Conclusiones}

La imagen sigue ocupando un lugar destacado en la vida de todas las personas. Funge como testigo, evidencia, recuerdo y memoria. Paradójicamente, en la caverna de Platón, en la que seguimos inmersos, vemos sin ver, consumimos sin entender.

Muchas ideas e hipótesis sobre la imagen ya no se ajustan al mundo tal cual es hoy. La invención de la cámara cambió la manera de ver de los seres humanos; esta nos dio a entender que el ser humano no era el centro del mundo. Pero el momento actual virtual y sélfico pone de nuevo nuestra propia imagen como el centro de todo. El espectro de lo visible en el encierro se limitó a registrar nuestro propio reflejo.

El fluir del tiempo y de la vida discurre frente a nuestros ojos, un tiempo metafórico que en imágenes podemos manipular: adelantar pero también atrasar o detener. Congelar la imagen, fragmentar el cuadro, reeditar la historia, resignificar, darle nuevos sentidos, un camino entre la ficción, la irrealidad o la mentira. Ahora, multitud de imágenes que nos atrapan y fascinan pueden ser vistas, compartidas y difundidas en simultáneo, como en una nueva versión cubista que nos hace ver todas las aristas, los distantes límites posibles, juntos y en el mismo instante. 
Vemos, narramos y contamos con la premura y el urgente vértigo del instante. Las imágenes se producen, se envían, se pierden, son anónimas, sin autoría, sin palabras y seguramente sin sentido ni significado. La reproductividad anunciada por Benjamín hoy discurre en cifras inimaginables. Los encuentros "invertidos" en el aula discurren con lo enigmático que supone el no saber y constatar la presencia real del otro.

Se producen sin duda narrativas sensibles desde la comunicación, el discernimiento, la razón, pero siempre nos quedaremos con la duda de si los contenidos, ideas, conceptos llegaron hasta el otro lado del "espejopantalla" sin disolverse y si lograron ser comprendidos, discutidos o refutados.

Por primera vez en la historia las imágenes son efímeras, volátiles, frágiles, ubicuas, accesibles, carecen de valor, incorpóreas, pero son libres. Nos envuelven, como las palabras o los abrazos, de manera vertiginosa.

El encuentro virtual de las y los profesores con sus estudiantes, en esas nuevas aulas "invertidas" a las que hemos tenido que recurrir de manera imprevista y acelerada, nos está permitiendo cierta conexión, pero también nos está generado profundas reflexiones sobre el lugar de la palabra, sobre los cuerpos en la pantalla, sobre los procesos de aprendizaje, sobre la calidad y eficacia de la comunicación con el otro/otra. Estas circunstancias sugieren nuevos retos pedagógicos y didácticos a docentes e instituciones.

Porque claramente el reto no es solo el de la conectividad en un país tan desigual en temas de accesibilidad. A lo que nos enfrentamos es a la evaluación permanente de lo que estamos haciendo, de generar una reflexión con y desde la imagen fotográfica, que es nuestro objeto de estudio, sobre su producción, sus narrativas y la circulación que hacemos de ellas en estos tiempos tan vertiginosos en los que estamos sumidos. 
Las fotografías son fragmentos de vivencias individuales que conjugan percepción, escucha, creación, lenguaje. Son historias únicas y dolencias emocionales que terminan convertidas en instantáneas que transmiten, que comunican, pero que en algunos casos transgreden e incluso transforman nuestros modos de ver y mirar.

La docencia universitaria permite explorar un mundo amplio en torno a la pedagogía del arte, concretamente de la fotografía. Las actuales circunstancias han posibilitado experimentar distintas metodologías, por novedosas y desconocidas para, de alguna manera, encauzar la formación de alumnas y alumnos hacia fines específicos, sean artísticos o comunicativos, en unos entornos virtuales que alejan los cuerpos y producen otras imágenes de una realidad no prevista.

Lo que se ha buscado es que cada estudiante encuentre en las pantallas su propia voz, su particular manera de narrar con imágenes que haga que su obra pueda distinguirse de la imagen masificada que vemos en la cultura visual hoy. Que cada uno indague en las particulares maneras de mirar, en buscar sus propias raíces y en dejarse sorprender con las cosas para poder narrar con su producción fotográfica en circunstancias tan inesperadas y sorprendentes.

El arte no es unívoco. Hoy más que nunca podemos decir que la situación que vivimos ocasionada por la pandemia nos está mostrando la obra de artistas que están transformando las formas de hacer y que subvierten lo anterior, lo que hasta ayer veíamos. Como docentes debemos evitar que las formas de ver y contar de los estudiantes se asemejen los de unos a los otros; debemos intentar que sean miradas personales, propias y no las miradas superficiales que inundan las redes sociales.

Los artistas con sus obras nos han señalado cambios de paradigmas y los fotógrafos con sus imágenes nos muestran los síntomas como expresión de 
los acontecimientos. Los docentes hemos tenido que asumir ambas cosas para lograr hacer comprensible a nuestros estudiantes todos estos cambios ocasionados por la pandemia.

Después de años de docencia universitaria en torno a la fotografía, hemos tenido que experimentar con distintas metodologías para poder lograr resultados pedagógicos con sentido, de modo que se consoliden maneras propias de narrar fotográficamente en circunstancias inusuales.

\section{Referencias}

Barthes, R. (1989). La cámara lúcida. Paidós Ibérica.

Benjamin, W. (2004). Sobre la fotografía. Pre-textos.

Berger, J. y Mohr, J. (2008). Otra manera de contar. Gustavo Gili.

Bosch, L. (2005). Esto que ves es un rostro. Curbet Comunicación Gráfica.

Peña Sarmiento, M., Múnera Barbosa, B., Sanabria, C., y Chaves, I. (2020). Cuatro cuentos incidentes. Question/Cuestión, 1, e330.

https://doi.org/10.24215/16696581e330

Chaves, J. I., Ruiz, G. y Múnera B. (2020). La imagen y la construcción de la memoria de las realidades que habitamos durante la pandemia. En T. Hidalgo, J. Herrero y Segarra, J. (coords.). Comunicación, periodismo y publicidad: retos profesionales en tiempos de crisis. Fragua.

Fontcuberta, J. (2016). La furia de las imágenes. Galaxia Gutemberg.

Machado, A. (2016). Antología poética. Alianza editorial.

Man Ray. (1929). Ma dernière photographie (Mi última fotografía). https://www.pinterest.fr/pin/443182419558068622/

Magritte, R. (1928). L'Image parfaite (La imagen perfecta). https://www.facebook.com/allmagritte/photos/a.1598328476916503/229416994 $\underline{0665683 /}$

Magritte, R. (1929). Le faux miroir (El espejo falso). https://www.moma.org/collection/works/78938 
Múnera, B., Sanabria, C., Peña, M. y Chaves, I. (2020). Cuatro cuentos incidentes. Question/Cuestión, 1, e330. https://doi.org/10.24215/16696581e330

Ritchin, F. (2010). Después de la fotografía. Serieve.

Sartre, J. P. (2016). El ser y la nada. Losada. 